\title{
Último Desejo e Testamento de Wilhelm Reich ${ }^{1}$
}

\author{
Sara Quenzer Matthiesen ${ }^{2}$ \\ Universidade Estadual Paulista - Rio Claro
}

\begin{abstract}
RESUMO- O objetivo desta tradução é contribuir para a divulgação do pensamento do médico psiquiatra e inicialmente, psicanalista, Wilhelm Reich. Nascido em 24 de março de 1897, em parte da Galícia pertencente ao Império austro-húngaro, Reich morreu na prisão em 03 de novembro de 1957 nos Estados Unidos da América. Contudo, poucos meses antes do ataque cardíaco que o levou à morte, Reich legou sua obra às “crianças do futuro” em testamento assinado em 08 de março de 1957, onde registrou seus últimos desejos sob o testemunho de Willian Moise, Michael Silvert e Willian Steig, temendo possíveis distorções, difamações, adulterações e destruição de seus escritos após a sua morte.
\end{abstract}

Palavras-chave: Wilhelm Reich; testamento; pensamento reichiano.

\section{Last Will and Testament of Wilhelm Reich}

\begin{abstract}
ABSIRACT - The aim of this translation is to contribute to the divulgation of the thoughts of the psychiatrist, initially psychoanalyst, Wilhelm Reich. Born on March 24, 1897 in the part of Galicia that then belonged to the Austro-Hungarian Empire, Reich died in prison on November 3, 1957 in the United States of America. However, few months before the heart attack that carried him to the death, he bequeathed his work to the "children of the future" in a testament signed on March 8,1957 , where he registered his last will by the testimony of Willian Moise, Michael Silvert and Willian Steig, afraid of possible distortion, slander, adulteration and destruction of his writings after his death.
\end{abstract}

Key words: Wilhelm Reich; testament; Reichian thought.

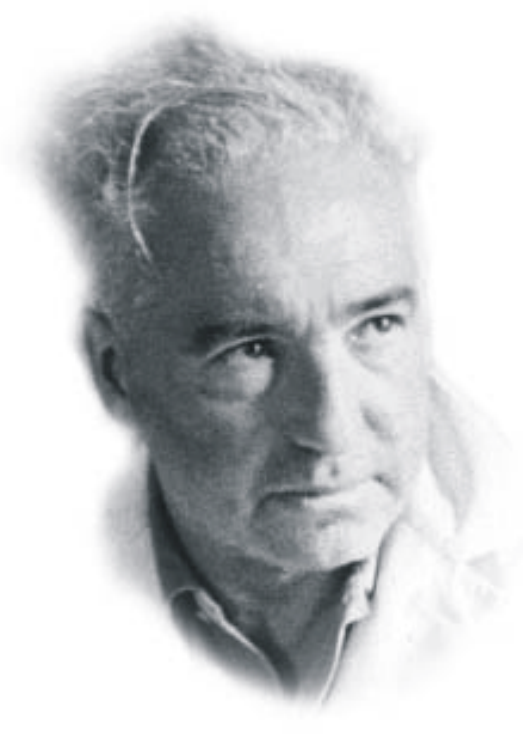

Wilhelm Reich ${ }^{3}$
1 Agradecemos a Mary Boyd Higgins, diretora do The Wilhelm Reich Museum, que concedeu em 7/7/00, autorização para publicação da tradução do original: Reich, Wilhelm. Last will and testament of Wilhelm Reich. Rangeley, 1957, 6p.

2 Endereço: Rua 5B, n. 312, ap. 31, Bairro Cidade Nova, Rio Claro, SP. CEP.:13.506-808. E-mail: saraqm@ @rc.unesp.br

3 As fotos que ilustram o artigo são de American College of Orgonomy, e foram extraídas do site http://www.wilhelmreich.com/index.html.

\section{Nota Introdutória}

Condenado em meados de 1956 sob a acusação da Food and Drug Administration - FDA de utilização ilegal do acumulador de orgone, Reich fez seu testamento em 8 de março de 1957, talvez, prevendo a aproximação de sua morte que viria a ocorrer em 3 de novembro deste mesmo ano. Se, para a eternidade, deixou uma obra que ultrapassa vinte livros e dezenas de artigos, ainda que pouco conhecidos, para as gerações futuras fez questão de preservar seus escritos e suas idéias, muitas das quais virão a público somente em 2007, quando, então, se completará 50 anos de sua morte. Para Eva - sua filha mais velha que seguiu seus passos no campo da medicina - Reich deixou uma função, a de ser curadora da Wilhelm Reich Infant Trust Fund e do Wilhelm Reich Museum cujo fim estava voltado às "crianças do futuro". Para Peter, seu filho mais novo, do casamento com Ilse Ollendorf - Reich registrou sua preocupação, já que na época de sua morte ele tinha apenas treze anos. Assim como para Eva, deixou-lhe alguns de seus pertences entre roupas, títulos, objetos de estimação, parte dos direitos autorais, além de um de seus rifles e equipamento fotográfico. A Lore - sua segunda filha do casamento com Annie Reich - ele nada deixou, a não ser uma cláusula que lhe impede, assim como a todo qualquer outro parente, a possibilidade de requerer qualquer coisa que lhe tenha pertencido. Foi assim, distribuindo o que tinha, preocupando-se com aqueles que amava e precavido quanto aos destinos de sua obra que Reich explicitou seus últimos desejos. Desejos que estavam relacionados a seu próprio funeral em Orgonon cujos detalhes, desde o som da "Ave Maria" de Schubert à prescrição na 


\section{S. Q. Matthiesen}

pedra de granito sobre seu túmulo, foram cuidadosamente prescritos. Não há como não ser triste a tradução de suas palavras. Nelas há todo o sofrimento humano, toda a amargura sofrida ao longo de seus sessenta anos de vida, embora, ao mesmo tempo, revelem certa dose de esperança e um otimismo inconfundível de que talvez um dia o mundo pudesse vir a ser melhor.

\section{Último Desejo}

Eu, Wilhelm Reich, residindo em Orgonon, Rangeley, Maine, por meio deste faço público e declaro este como Meu Último Desejo e Testamento:

1. Nenhuma vingança pessoal nem desrespeito para as muitas amabilidades que desfrutei durante minha vida determinam minhas decisões neste desejo. Estando em pleno domínio de meu julgamento de pessoas e assuntos sociais e estando lúcido, considerei a transmissão segura para futuras gerações de um vasto império de realização científica como o guia de minhas últimas disposições. No meu modo de ver, a tarefa fundamental a ser cumprida era salvaguardar a verdade sobre minha vida e trabalho contra a distorção e a difamação após a minha morte.

2. Eu por meio deste revogo todos os testamentos anteriores feitos por mim a qualquer momento.

3. Instruo que todas as dívidas recentes e despesas funerárias sejam pagas, com exceção dos pedidos específicos feitos daqui por diante; eu por meio deste dou, outorgo e lego todo o resto, resíduo e lembranças remanescente de minhas posses, tanto imobiliárias quanto pessoais, de qualquer natureza e qualquer tipo e onde quer que se situe, do qual eu possa morrer empossado e dotado ou para qual eu possa então ter direito, para meu Curador nomeado daqui por diante, e para curadores sucessores que possam ser indicados para administrar o mesmo, para ter e para controlar a dita propriedade e para gerenciar, vender, investir na mesma e para arrecadar o lucro, rendimento, dividendos e produtos provindos da dita propriedade para os usos e disposições incluídos a seguir:

a. A Fundação deverá ser segurada e administrada sob o nome de Fundação Wilhelm Reich de Proteção à Infância.

b. As despesas administrativas da dita Fundação nunca deverão exceder $20 \%$ da renda total.

c. Para operar e manter a propriedade em Orgonon sob o nome e estilo do Museu Wilhelm Reich.

Durante os anos seguintes a 1949 minha vida seguiu seu curso dentro e ao redor das paredes do Observatório de Energia Orgone. Eu mesmo supervisionei as obras por dois verões; paguei o valor superior a US\$ 35,000 com as posses pessoais para a construção. Coletei todo o material pertinente tais como instrumentos que serviram à Descoberta da Energia Vital, os documentos que foram testemunhas de trabalhos de cerca de 30 anos e a biblioteca de alguns milhares de volumes, arduamente coletados durante este mesmo espaço de tempo e amplamente usados em minhas pesquisas e escritos, as pinturas, cerca de 25 delas, itens pequenos os quais amei e tratei com carinho durante a minha vida tais como a bengala africana entalhada que me deu Malinowski, o retrato de Sigmund Freud, alguns vasos não valiosos mas expressivos, a "Rock Woman" de Jo Jenks, o "Zaenn't Weh'Bauer" entalhado a 12,000 pés acima do nível do mar em algum refúgio montanhoso na Áustria - todas essas coisas e coisas similares devem permanecer onde estão agora a fim de preservar algo do ambiente em que a Descoberta da Energia Vital se efetuou durante décadas.

As dependências devem ser conservadas arrumadas e limpas e consertos não devem ser negligenciados. Os custos de manutenção, consertos, serviços e salários devem ser pagos por esta Fundação.

d. A fim de permitir que o futuro estudante do OCEANO DE ENERGIA CÓSMICA PRIMORDIAL, A ENERGIA VITAL descoberta e desenvolvida por mim, obtenha uma imagem verdadeira de minhas realizações, erros, suposições errôneas, tendências pioneiras básicas, minha vida pessoal, minha infância, etc., eu por meio deste instruo que sob nenhuma circunstância ou qualquer pretexto quaisquer documentos, manuscritos ou diários, achados em minha biblioteca entre os arquivos ou em qualquer outro lugar deverão ser alterados, omitidos, destruídos, ampliados ou falsificados em qualquer modo imaginável. A tendência do homem, nascido do medo, de "dar-se bem com seu semelhante" a qualquer preço e esconder assuntos desagradáveis é esmagadoramente forte. Para salvaguardar-se contra esta tendência, desastrosa para a verdade histórica, meu escritório, incluindo a biblioteca e arquivos, devem ser lacrados logo após a minha morte pelas autoridades legais apropriadas e ninguém deve ter permissão para examinar meus escritos até que meu Curador, daqui por diante nomeado, seja devidamente apontado, qualificado e assuma o controle e a custódia a partir de então.

Estes documentos são de crucial importância para o futuro das gerações dos que acabam de nascer. Há muitas pessoas emocionalmente doentes que tentarão arruinar minha reputação independente do que possa ocorrer com os bebês, apenas para que suas vidas pessoais possam permanecer escondidas na escuridão de uma era refugada dos Stalins e dos Hitlers.

e. Eu portanto instruo meu Curador e seus sucessores que absolutamente nada deve ser mudado em quaisquer dos documentos e que eles devem ser guardados e armazenados por 50 anos para assegurar sua integridade contra a destruição e a falsificação por parte de qualquer interessado na falsificação e destruição da verdade histórica. ${ }^{4}$

4 Nota da tradutora: Na verdade, a interpretação de que esse material deveria vir a público apenas em 2007 foi realizada por Mary Boyd Higgins (curadora atual) das palavras originais de Reich - "put away and stored for 50 years" - contestada judicialmente por Eva Reich, embora sem sucesso. Cf Sharaf (1983, p. 480). 
f. Estas diretrizes são estabelecidas por mim exclusivamente para a preservação da verdade documentada como eu a vivenciei durante minha vida.

g. Durante toda a minha vida eu amei bebês, crianças e adolescentes, e também sempre fui amado e compreendido por eles. Bebês costumavam sorrir para mim porque eu tinha profundo contato com eles e crianças de dois ou três anos muito freqüentemente costumavam ficar pensativas e sérias quando me olhavam. Este foi um dos grandes felizes privilégios de minha vida, e quero expressar de alguma forma meus agradecimentos por aquele amor a mim conferido por meus pequenos amigos. Possa o destino e a Energia viva do grande Oceano, da qual eles vieram e para a qual eles devem retornar mais cedo ou mais tarde, conceder-lhes felicidade, e contentamento e liberdade durante suas vidas. Espero ter contribuído com boa cota para sua felicidade futura.

Para esse fim, a Fundação Wilhelm Reich de Proteção à Infância deve ser principalmente voltada e seguramente dirigida.

h. Lego a pequena casa abaixo da rodovia em frente ao Laboratório dos Estudantes de Orgonon para minha filha Dra. Eva Reich.

i. Os $80 \%$ de toda a renda, lucros ou rendimentos devidos a mim e à Fundação provenientes de direitos autorais em instrumentos originários de minhas descobertas devem ser destinados para o cuidado de bebês em qualquer lugar, para a segurança legal dos bebês, crianças e adolescentes em dificuldade emocional, social, paterna, médica, legal, educacional, profissional ou outra necessidade. Parte dos rendimentos pode ser usada para a pesquisa orgonômica básica.

j. Se a Fundação Wilhelm Reich de Proteção à Infância falhar no propósito, então meu Curador, após cuidadosa deliberação do assunto, deverá transferir todas as posses da dita Fundação para uma agência apropriada designada e capaz de tratar tais assuntos.

4. Meu filho Peter precisará de suporte financeiro por muitos anos em sua educação para a atividade social adulta. Eu portanto instruo que:

a. Todas as Ações do Tesouro dos Estados Unidos da América, comprados e emitidos em nome de Peter não devem ser usadas antes que as mesmas estejam completamente vencidas.

b. Eu por meio deste especificamente dou, outorgo e lego algumas ações emitidas em meu nome, a meu filho Peter Reich como depositário após a minha morte, a Ilse Ollendorf a custódia antes disso ou, no evento de sua morte, a Eva Reich a custódia, para ter e para gerir as mesmas e receber a renda, lucros e principal disso, no montante de US\$150 por mês.

c. Eu por meio deste dou, outorgo e lego a Peter qualquer um dos dois de meus rifles que ele escolha, e junto com esses rifles tais acessórios como cinturão de cartucheira e material de limpeza como ele desejar; meu equipamento fotográfico; assim como quais-

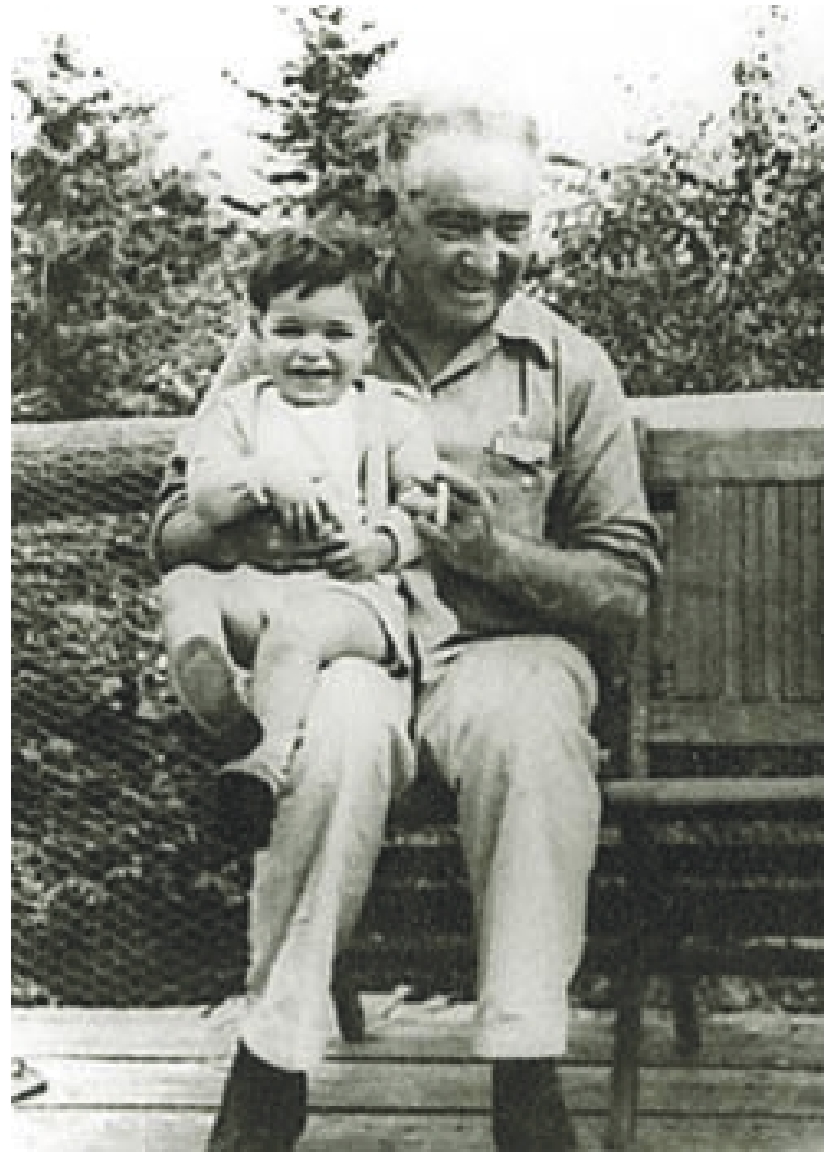

Wilhelm Reich e seu filho Peter, 24 de Março de 1947

quer das minhas roupas que ele possa desejar. Por toda a sua vida, ou até que manifeste o desejo de não mais usá-la antes de sua morte, posse da chamada "casa de baixo" em Orgonon com sua mobília, bem como a área que a cerca, de cerca de 10 acres, mais ou menos, sujeito a uma licença a Eva Reich para usar a casa se ela desejar; com a morte de Peter ou caso decida não usá-la pessoalmente, ou caso não a utilize para fins pessoais por um período de 3 anos, a casa de baixo deverá reverter para a Fundação Wilhelm Reich de Proteção à Infância para uso da Fundação como casa de verão para crianças; sob nenhuma circunstância deve tal casa de verão estar na posse, custódia ou controle de nenhuma outra pessoa que não Peter, ou Eva Reich, se ela assim o desejar, como acima estabelecido.

5. Eu por meio deste dou, outorgo e lego a minha filha Eva US $\$ 10.000$, qualquer peça de minha mobília pessoal que ela possa desejar.

6. Eu por meio deste dou, outorgo e lego para Aurora Karrer US\$ 4,000 e meu automóvel Chrysler 300, 1955.

7. Eu por meio deste dou, outorgo e lego para minha filha Eva e meu filho Peter, compartilhar e repartir igualmente $10 \%$ de todos os direitos autorais que possam ser pagos por ocasião de minha morte ou depois dela, em que tais direitos autorais signifiquem renda proveniente de minhas descobertas, livros ou traduções de livros. 


\section{S. Q. Matthiesen}

8. Eu por meio deste nomeio, constituo e aponto Eva Reich M.D. como Curadora deste meu último Desejo e Testamento e como minha Curadora instruo que outra pessoa não possa requerer qualquer ação como se fosse tal Executor ou Curador, qualquer disposição em contrário será impugnada; e também instruo que na execução da Fundação Wilhelm Reich de Proteção à Infância, se meu dito Curador por um instrumento escrito apontar um sucessor, ou no caso de meu Curador renunciar ou tornar-se incapacitado, ou por instrumento testamentário apontar um sucessor por ocasião de sua morte, o dito sucessor e todos os meus curadores deverão, a partir de então, sucessivamente ter o mesmo poder; sendo minha única instrução a este respeito que tais curadores sucessores devem agir de acordo com as diretrizes por mim expressadas. ${ }^{5}$

9. Eu não nutro nenhum ressentimento contra meus parentes. A maioria deles eu não tenho encontrado há muitas décadas. Desde que eu não conheço nenhum parente meu que estaria apto a agir de acordo com as diretrizes principais deste testamento, que é Salvaguardar a Verdade Total sobre minha Vida e Trabalho, eu deserdo para todo o sempre e de todas as formas TODOS os meus parentes consangüíneos e por casamento (tanto legais como em comum) tanto por parte de meu pai como de minha mãe. Eles não devem ter direito sobre o que quer que seja, não importa quem, em que forma ou sob quaisquer pretextos a quaisquer de minhas posses presentes ou futuras, ou às posses da Fundação Wilhelm Reich de Proteção à Infância que leva meu nome e foi fundada para preservar minhas descobertas; nenhuma reivindicação em qualquer base ou momento que seja. Isso inclui meus próprios filhos, com as exceções citadas acima.

10. Este testamento e todas as disposições nele contidas não devem ser total ou parcialmente revogadas ou tornadas total ou parcialmente sem efeito ou de outra forma afetadas pelo subseqüente nascimento de filho ou filhos meus.

11. Eu não desejo ser enterrado em nenhum cemitério, mas em Orgonon embaixo da varanda aberta, voltada para o leste, ou no Abrigo de Pedra no sul. O busto de Jo Jenks pertencente a mim deve ser posto sobre meu túmulo. A inscrição deverá ser em granito e deve conter os seguintes dizeres: Wilhelm Reich, nascido em 24 de Março, 1897 , morto em, Nenhuma cerimônia religiosa deverá ser realizada. A "Ave Maria” de Schubert, cantada por Marian Anderson, deverá ser tocada.

5 Nota da tradutora: Ao que consta, Eva Reich, em 1959, passou esta responsabilidade para Mary Boyd Higgins, atual curadora da "The Wilhelm Reich Infant Trust" [Fundação Wilhelm Reich de Proteção à Infância) e do "Wilhelm Reich Museum", local de veraneio e de reconhecida beleza por aquelas que visitam o Maine, E.U.A.

6 Nota da tradutora: Willian Moise era marido de sua filha Eva; Michael Silvert, seu assistente, condenado a um ano e um dia, suicidando-se em maio de 1958, cinco meses após ter deixado a prisão; Willian Steig era seu amigo.
EM TESTEMUNHO DISTO eu agora efetuo e selo este documento no oitavo dia de Março, 1957.

Wilhelm Reich (L.S.)

Testemunhas:

Willian Moise

Michael Silvert

Willian Steig ${ }^{6}$

Assinado, selado, publicado e declarado pelo acima citado testador como seu último Desejo e Testamento, e nós, a seu pedido e em sua presença e na presença uns dos outros, assinamos agora nossos nomes como testemunhas subscritas neste de Março de 1957.

Willian Moise, residente a R. F.D.1 Box 721 Alexandria, Va. Michael Silvert, residente a 50 Grove St., N.Y.14, N.Y. Willian Steig, residente a R. D.2.,Cream Ridge, N.J.

\section{Referências}

Reich, W. (1957). Last will and testament of Wilhelm Reich. Rangeley.

Sharaf, M. (1983). Fury on earth: A biography of Wilhelm Reich. Nova York: Da Capo Press. 